\title{
Understanding the effect of carbon nanotube functionalization on copper electrodeposition
}

\author{
Ewa Kazimierska ${ }^{1}$ D Enrico Andreoli ${ }^{1}$ - Andrew R. Barron ${ }^{1,2,3}$
}

Received: 15 January 2019 / Accepted: 9 May 2019 / Published online: 20 May 2019

(C) The Author(s) 2019

\begin{abstract}
The dynamics of electrochemical deposition and dissolution of copper in the presence of functionalized multiwalled carbon nanotubes in solution has been studied in detail using an electrochemical quartz crystal microbalance. Results demonstrate the central role of carbon nanotube functionalization on the values of mass and current densities of copper deposition. Amine functionalization increases competitive hydrogen evolution without significantly affecting the total amount of deposited copper, whereas carboxylic functionalization clearly enhances the deposition of larger amounts of smoother copper deposits. Molar mass analysis of deposited species reveals interactions of carbon nanotubes with the electrode surface dependent on the type of functionalization. The effect of carbon nanotube functionalization should be closely considered in the development of electrochemical strategies for the integration of carbon nanotubes in metallic copper.
\end{abstract}

\section{Graphical Abstract}
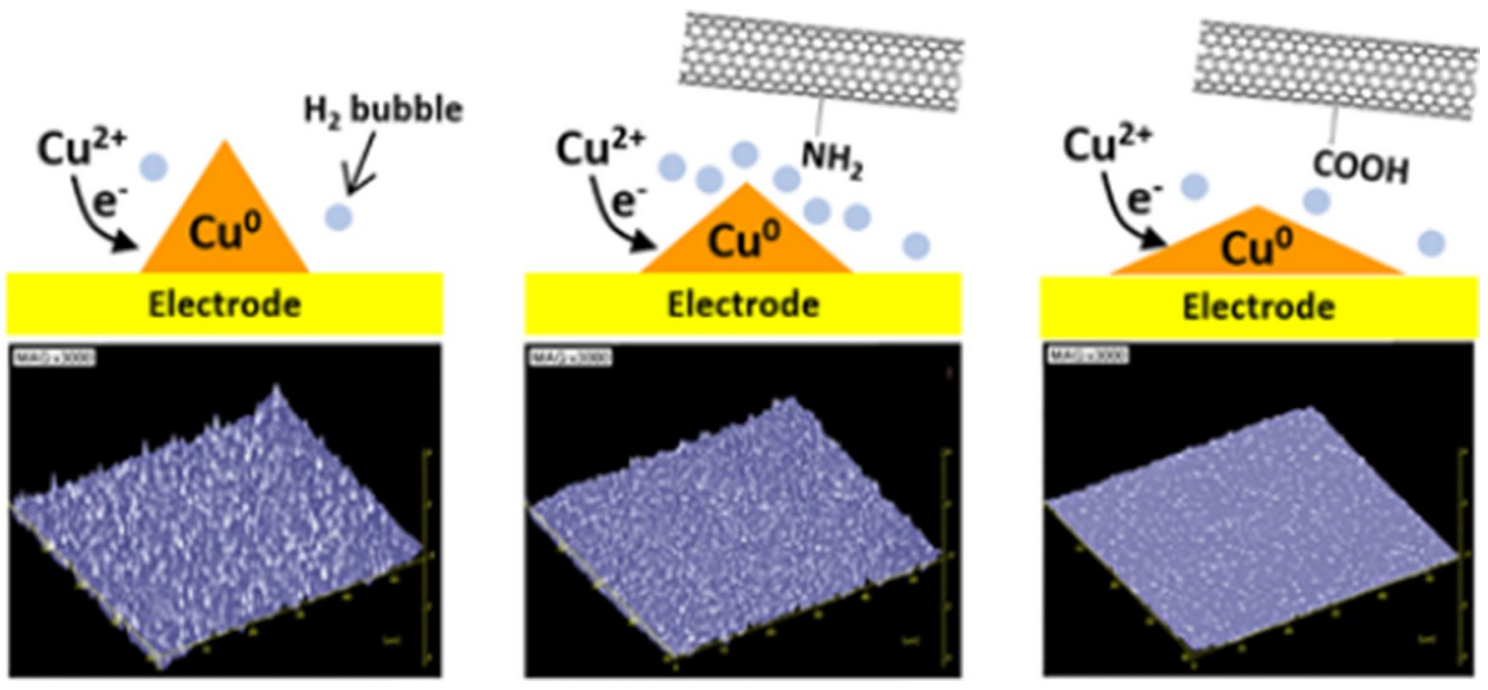

Keywords Copper $\cdot$ Carbon nanotubes $\cdot$ Composite $\cdot$ Functionalization $\cdot$ Electrodeposition

Electronic supplementary material The online version of this article (https://doi.org/10.1007/s10800-019-01318-x) contains supplementary material, which is available to authorized users.

Ewa Kazimierska

ewa.kazimierska@swansea.ac.uk

Extended author information available on the last page of the article

\section{Introduction}

Copper is key to numerous modern technologies because of its high electrical and thermal conductivity; however, a relentless increase in performance demand is fueling research into improving its properties particularly in the electronic industry where the ampacity of copper is foreseen 
to limit the further miniaturization of microprocessors. Ampacity is the maximum electrical current a conductor can safely carry without sustaining deterioration leading to failure. High-ampacity materials are critical in modern microelectronics where interconnects have shrunk to the nanometer scale, given the cross section and resulting high current densities exceeding the breakdown limit of copper. Copper-carbon nanotubes $(\mathrm{Cu}-\mathrm{CNT})$ composites show improved ampacity and hold promise to overcome this limit $[1,2]$, while $\mathrm{Cu}-\mathrm{CNT}$ interconnects have already been experimentally demonstrated [3, 4].

Copper-single-walled carbon nanotube $(\mathrm{Cu}-\mathrm{SWCNT})$ composites developed by Hata et al. achieved ampacities of $600 \times 10^{6} \mathrm{~A} \mathrm{~cm}^{-2}$, two orders of magnitude higher than those of pure copper [1]. The improvement is related to the phonon contribution of CNTs to thermal conductivity and suppressed electromigration, thanks to the electron wind shielding effect of CNTs [1]. The Cu-SWCNT wire could operate at $100 \times 10^{6} \mathrm{~A} \mathrm{~cm}^{-2}$ for 50 days with an increase of resistivity of only $10 \%$; the electrical conductivity was comparable to that of pure copper, $2 \times 10^{5} \mathrm{~S} \mathrm{~cm}^{-1}$ and $5.8 \times 10^{5}$ $\mathrm{S} \mathrm{cm}^{-1}$, respectively [1]. Recently, the same authors manufactured light-weight copper-multiwalled carbon nanotube (Cu-MWCNT) wires using industrially compatible copper deposition processes and commercial CNTs achieving ampacities $28 \%$ higher than bulk $\mathrm{Cu}$ [5].

A key challenge to the preparation of $\mathrm{Cu}-\mathrm{CNT}$ composites is the integration of CNTs in the copper matrix. The large mismatch in surface free energy between the two materials (72.9 and $1650 \mathrm{~mJ} \mathrm{~m}^{-2}$ for nanocarbon and copper, respectively [2]) represents an intrinsic barrier to compatibilization. This lack of affinity is also the cause of poor electrical contact at the metal/CNT interface, a major issue that needs to be addressed [6]. While first principles calculations support the use of a second metal to improve charge transport across the $\mathrm{Cu} / \mathrm{CNT}$ interface [7] (for example by adding chromium to bridge CNTs [8] or to form carbides [9, 10] and create a better ohmic interface), it is still challenging to experimentally document the effect of different CNTs on the formation of $\mathrm{Cu}-\mathrm{CNT}$ composites.

$\mathrm{Cu}-\mathrm{CNT}$ composites can be prepared following various procedures including powder processing, chemical deposition, melting and solidification, spray techniques, and other novel approaches [11,12]. Chemical deposition is of interest since it is usually performed in milder conditions preserving the electrical and thermal propertied of CNTs. Copper electroless deposition on CNTs using chemical reducing agents in place of an external power source is a relatively unexplored approach [2]. Arai et al. prepared $\mathrm{Cu}-\mathrm{MWCNT}$ and $\mathrm{Cu}-\mathrm{SWCNT}$ composites using glyoxylic acid as a reducing agent; however, surfactants and high-energy disaggregation methods (e.g., mechanical atomization) were necessary to obtain well-dispersed CNTs in copper matrix [12-14]. Using a different approach, our group has successfully transferred expertise in electroless deposition of copper from alumina to CNT surfaces $[15,16]$. Covalent functionalization with nitrogen bearing molecules, such as isonicotinic acid and pyridine on the surface of alumina and SWCNTs, respectively, allowed an even distribution of copper particles thanks to seeding effect of nitrogen functionalities [16]. On the other hand, CNT functionalization can also affect electrodeposition; for this reason, we have performed this study to closely examine the effect of CNT functionalization during electrodeposition of copper.

Compared to electroless deposition, co-deposition of $\mathrm{Cu}$ and CNTs on cathodically polarized surfaces is a widespread approach $[2,11]$. Covalent and non-covalent modification of CNTs surface is common to many studies to improve the dispersibility of otherwise hydrophobic carbon materials in water. Poly(acrylic acid) (PAAH) was used in the electrodeposition of $\mathrm{Cu}-\mathrm{MWCNT}$ composite films achieving a maximum CNT loading of about 0.5 wt $\%[17,18]$, whereas covalent followed by wrapping with poly(diallyldimethylammonium chloride) (PDDA) to obtain positively charged nanotubes was applied to produce composites with about $5 \mathrm{wt} \%$ CNTs [19]. Different experimental conditions such as CNT concentration in copper plating bath, temperature, potential, current density, are known to influence the deposition and CNT loading, less instead is known on the interaction between copper and modified CNT during deposition. The two-step adsorption model of Guglielmi was shown to apply only in the case of low CNT solution concentration since at higher concentrations more PAAH dispersant had to be used inhibiting copper deposition [20]. A mechanism of CNT incorporation in copper has also been proposed for PAAH-wrapped MWCNTs where the direction of growth of copper sheets is not altered by the nanotubes, resulting in the sheets growing undisturbed around the CNTs [21]. In a more recent work, the tip effect is identified as the cause of copper particles nucleation at the ends of CNTs and surface defects as the active sites of carboxylated CNTs aiding to the further growth of copper on functional groups during electrodeposition [22]. Yet a study of the effect of CNT functionalization on the deposition of copper is missing.

In this work, we used an electrochemical quartz crystal microbalance (EQCM) to follow real time the deposition and dissolution of copper in the presence of dispersions of functionalized CNTs in solution. EQCM allows to correlate columbic charge of deposition/dissolution to deposited/dissolved mass. The dynamics of copper deposition is shown to be influenced by the nature of functionalization present on the nanotubes with carboxylic functions better suited to enhance copper deposition. Furthermore, we successfully detected the subtle effects of CNTs functionalization on competitive hydrogen evolution and resulting morphological 
changes of the deposits. We consider this new insight instrumental to a better understanding of the phenomena involved in the stages preliminary to the incorporation of CNTs in the copper matrix.

\section{Experimental}

Copper(II) sulfate pentahydrate ( $\geq 99.0 \%)$ and concentrated sulfuric acid (95-98\%) were purchased from Sigma-Aldrich and used as received. Amine-functionalized multiwalled carbon nanotubes $\left(\mathrm{H}_{2} \mathrm{~N}-\mathrm{MWNCTs}\right)$ and carboxyl-functionalized multiwalled carbon nanotubes $\left(\mathrm{HO}_{2} \mathrm{C}-\mathrm{MWCNTs}\right)$ were obtained from Nanocyl SA (Belgium). Both types of carbon nanotubes were prepared via catalytic chemical vapor deposition and purified to a carbon content $>95 \%$. The average diameter, average length, and degree of surface functionalization were $9.5 \mathrm{~nm}, 1.0 \mu \mathrm{m}$, and $>0.6 \%$, respectively, for $\mathrm{H}_{2} \mathrm{~N}-\mathrm{MWNCTs}$; and $9.5 \mathrm{~nm}, 1.5 \mu \mathrm{m}$, and $>8.0 \%$ for $\mathrm{HO}_{2} \mathrm{C}-\mathrm{MWCNTs}$. All solutions were prepared with deionized water obtained with an Elix Milliport AFS 15E Water Purification System $\left(\rho>15 \mathrm{M} \Omega \mathrm{cm}^{-1}\right)$.

A stock solution of $10 \mathrm{mM} \mathrm{CuSO}_{4} / 0.05 \mathrm{M} \mathrm{H}_{2} \mathrm{SO}_{4}(\mathrm{pH} 1)$ was prepared. Sulfuric acid was added to prevent formation of copper oxide and to assure smoother deposits. In a centrifuge tube, $40 \mathrm{ml}$ of stock solution was added to a $2-3 \mathrm{mg}$ aliquot of $\mathrm{H}_{2} \mathrm{~N}$-MWNCTs (or $\mathrm{HO}_{2} \mathrm{C}-\mathrm{MWCNTs}$ ) and sonicated for $60 \mathrm{~min}$ in $5 \mathrm{~s}$ pulse mode at $20 \%$ amplitude using a Cole-Parmer 500-Watt ultrasonic homogenizer. The resulting CNT dispersion was centrifuged for $20 \mathrm{~min}$ at $5000 \mathrm{rpm}$ (Thermo Scientific Heraeus Megafuge 16) with most of the nanotubes settling at the bottom of the centrifuge tube. The dark gray supernatant containing dispersed CNTs was carefully transferred into a clean vial. Utmost care was taken to avoid re-suspension of CNTs but a small number of visible nanotube bundles were also transferred; these were allowed to settle before using the supernatant solution for electrodeposition of copper. Fresh dispersions of carbon nanotubes were prepared before each electrochemical experiment.

Deposition/dissolution of copper was performed using a CH Instruments CHI440c time-resolved EQCM on goldcoated quartz crystal electrodes (electrode area $0.205 \mathrm{~cm}^{2}$, fundamental frequency 7.995 MHz). A Teflon cell was used with a $\mathrm{Ag} / \mathrm{AgCl} / 1.0 \mathrm{M} \mathrm{KCl}$ reference electrode and a $\mathrm{Pt}$ wire counter electrode. All potentials reported in this study are referred to $\mathrm{Ag} / \mathrm{AgCl} / 1.0 \mathrm{M} \mathrm{KCl}(0.222 \mathrm{~V}$ vs. SHE) with cathodic current taken as positive, and negative potentials plotted to the right [23] (US convention [24]). Working electrodes were rinsed several times with purified water and dried in clean airflow before deposition. Cyclic voltammograms of copper deposition/dissolution were recorded in the potential range going from 0.3 to $-0.3 \mathrm{~V}$ at a scan rate of $5 \mathrm{mV} \mathrm{s}^{-1}$. The specific potential window was chosen since it allowed to monitor full-closed cycles of deposition and dissolution of copper while using a low oxidation potential. Samples for copper morphology and roughness characterization were prepared using four full voltammetric cycles, terminating the fifth cycle at $0 \mathrm{~V}$ to maximize the amount of deposit copper. The morphology and the surface roughness of copper deposits were characterized with a Hitachi TM3030Plus scanning electron microscope equipped with Hitachi map 3D visualization software.

\section{Results and discussion}

\subsection{Electrodeposition of copper}

The dynamics of deposition/dissolution of copper on EQCM gold electrodes was studied using cyclic voltammetry while scanning the potential between 0.30 and $-0.30 \mathrm{~V}$ at a scan rate of $5 \mathrm{mV} \mathrm{s}^{-1}$ in $10 \mathrm{mM} \mathrm{CuSO}_{4} / 0.05 \mathrm{M} \mathrm{H}_{2} \mathrm{SO}_{4}$ solutions. Both current flow $(j)$ and mass change $(m)$ at the working electrode were recorded; the first cycle is shown in Fig. 1. The potential of a pristine electrode was initially scanned in the cathodic direction with almost no current recorded until above $0 \mathrm{~V}$ where the current started increasing to peak at about $-0.15 \mathrm{~V}$ (Fig. 1a). This peak corresponds to the reduction of $\mathrm{Cu}(\mathrm{II})$ ions to $\mathrm{Cu}(0)$ metal, i.e., the half reaction $\mathrm{Cu}^{2+}+2 \mathrm{e}^{-} \rightarrow \mathrm{Cu}^{0}$. The decrease of current registered from -0.15 to $-0.30 \mathrm{~V}$ is due to the finite and limited diffusion of copper ions from the bulk of the solution to the electrode surface where the $\mathrm{Cu}(\mathrm{II})$ ions concentration dropped to zero.

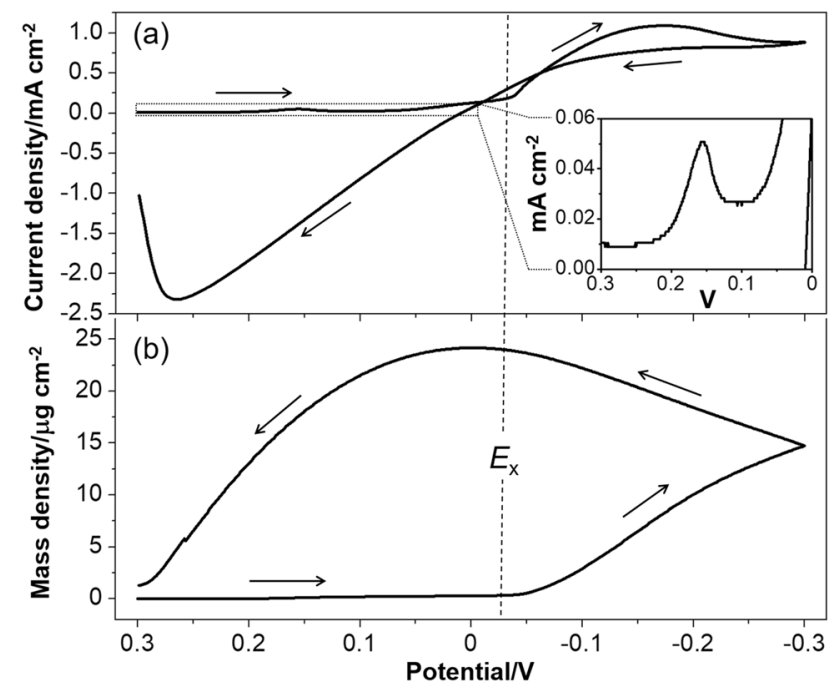

Fig. 1 Current and mass responses for the electrodeposition of copper on a gold EQCM electrode. a First cyclic voltammogram and corresponding $\mathbf{b}$ mass change measured during deposition in $10 \mathrm{mM}$ $\mathrm{CuSO}_{4} / 0.05 \mathrm{M} \mathrm{H}_{2} \mathrm{SO}_{4}$. The inset shows the peak of underpotential deposition of copper recorded during the cathodic sweep 
During the anodic sweep, going from -0.30 to $0.30 \mathrm{~V}$, a sustained reduction current was observed up until $0 \mathrm{~V}$ to revert to oxidation current in the remaining part of the cycle corresponding to the dissolution of $\mathrm{Cu}(0)$ to $\mathrm{Cu}$ (II) ions.

This behavior is in excellent agreement with that reported in literature [25]; cyclic voltammograms of copper deposition/dissolution in acidic $\left(\mathrm{H}_{2} \mathrm{SO}_{4}\right)$ aqueous solutions are characterized by a crossover potential $\left(E_{\mathrm{x}}\right)$ where anodic and cathodic traces overlap (Fig. 1a). This potential has been previously found at around $-0.10 \mathrm{~V}$ versus $\mathrm{Cu} / \mathrm{CuSO}_{4}$ [25], corresponding to about -0.03 versus $\mathrm{Ag} / \mathrm{AgCl}$ in the present case. The change of mass at the working electrode supports the dynamics discussed for the current flow (Fig. 1b). During the initial cathodic sweep, a significant increase of mass was recorded only after reaching about $-0.05 \mathrm{~V}$ in agreement with the start of reduction current. The mass of copper deposited on the electrode was about $15 \mu \mathrm{g} \mathrm{cm}-2$ when the potential reached $-0.30 \mathrm{~V}$ and the sweep switched to anodic. During the first half of the anodic sweep, going from -0.30 to $0 \mathrm{~V}$, copper ions were still reduced taking the mass deposited at the electrode just below $25 \mu \mathrm{g} \mathrm{cm}^{-2}$ corresponding to about $80 \mathrm{nmol}$ of deposited copper metal. As the oxidation potential went above $0 \mathrm{~V}$, copper started rapidly dissolving in solution taking the mass of the electrode almost back to its initial value. A small amount of copper (1 $\left.\mu \mathrm{g} \mathrm{cm}{ }^{-2}, 3 \mathrm{nmol}\right)$ was purposely left on the electrode since we observed its facilitating seeding effect on the subsequent cycles. This seeding layer is copper deposited at the start of the first cycle where a cathodic peak of underpotential deposition is observed between 0.20 and $0.10 \mathrm{~V}$ [26], as magnified in the inset of Fig. 1a. Figure S1a, in the Electronic Supplementary Material (ESM), shows all five cycles of copper electrodeposition/dissolution, the first cyclic voltammogram (Fig. S1a, black trace) corresponding to that shown in Fig. 1a. The overall shape of the second voltammogram (Fig. S1a, red trace) reassembles that of the first; however, the maximum deposited mass is now around $35 \mu \mathrm{g} \mathrm{cm}{ }^{-2}$ (Fig. S2a). Consequently, upon oxidation a larger amount of deposited copper is left on the electrode at $0.30 \mathrm{~V}$, which dissolves away at the start of third cycle (Fig. S1a, blue trace) to keep a fixed amount of seeding copper on the electrode available in all remaining cycles. Figure S2a confirms the dissolution of the extra deposited copper at the start of the cathodic sweeps with large anodic currents visible in cycles three, four, and five.

Additional information of the dynamics of copper deposition/dissolution can be obtained from plotting the mass change $(m)$ at the working electrode against the columbic charge $(q)$ used during the electrochemical cycle, as shown in Fig. 2. This plot is useful since the slope of the curve $m / q=M /(z F)$, where $M$ is the molar mass of the deposited species, $z$ is the number of electrons required to reduce one of such species, and $F$ is the Faraday constant (the electric

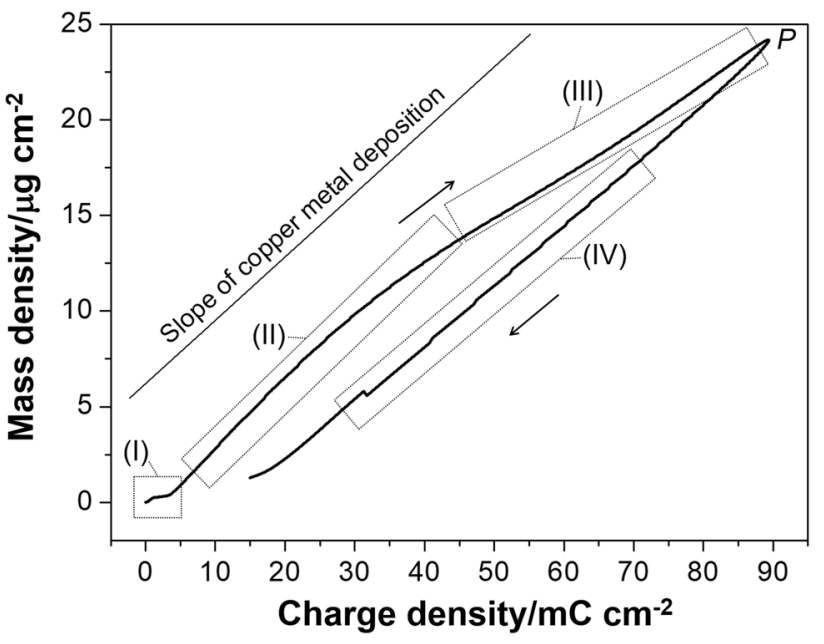

Fig. 2 Mass-charge curve for the deposition/dissolution of copper during the first voltammetric cycle shown in Fig. 1. Sections (I), (II), (III), and (IV) correspond to different stages of copper deposition/ dissolution, as discussed in the text. The straight line labeled "slope of copper metal deposition" shows the slope for the deposition/dissolution of copper only, i.e., in the absence of any other competitive faradaic process

charge of one mole of electrons, i.e., $96,485 \mathrm{C} \mathrm{mol}^{-1}$ ). If copper is the only species deposited/dissolved during the cathodic/anodic sweeps, the slope of the curve should be like that of the reference line drawn for pure copper named "slope of copper metal deposition" in the plot. In Fig. 2, there is good agreement between the overall slope of the experimental curve and that of the reference line, especially in the dissolution part of the curve that goes from about 90 back to $15 \mathrm{mC} \mathrm{cm}^{-2}$. It follows that the main species deposited on and dissolved from the electrode is copper, as one would expect. Deviation from the slope of copper metal deposition and other interesting features of the mass-charge curve can be better highlighted and explained when the molar mass of the deposited species is calculated from the slope of the $m-q$ curve (i.e., Eq. 1) and plotted against the voltage scanned during the first cycle, as shown in Fig. 3a.

$M=z F$ slope $=z F(m / q)$.

Figure $3 \mathrm{a}$ is an alternative way of presenting the data shown in the two plots of Fig. 1. While Fig. 1 gives the current flow and mass change during copper reduction/oxidation as the voltage is scanned, Fig. 3a shows the change in molar mass of deposited/dissolved species for the same processes in the same voltage range (the molar mass values are calculated from the slope of the $m-q$ curve in Fig. 2, as previously explained). Four key sections labeled (I), (II), (III), and (IV) are identified in the plot, the same labels are placed on the $m-q$ curve in Fig. 2 to help correlate the two plots. Before addressing the content and meaning of 

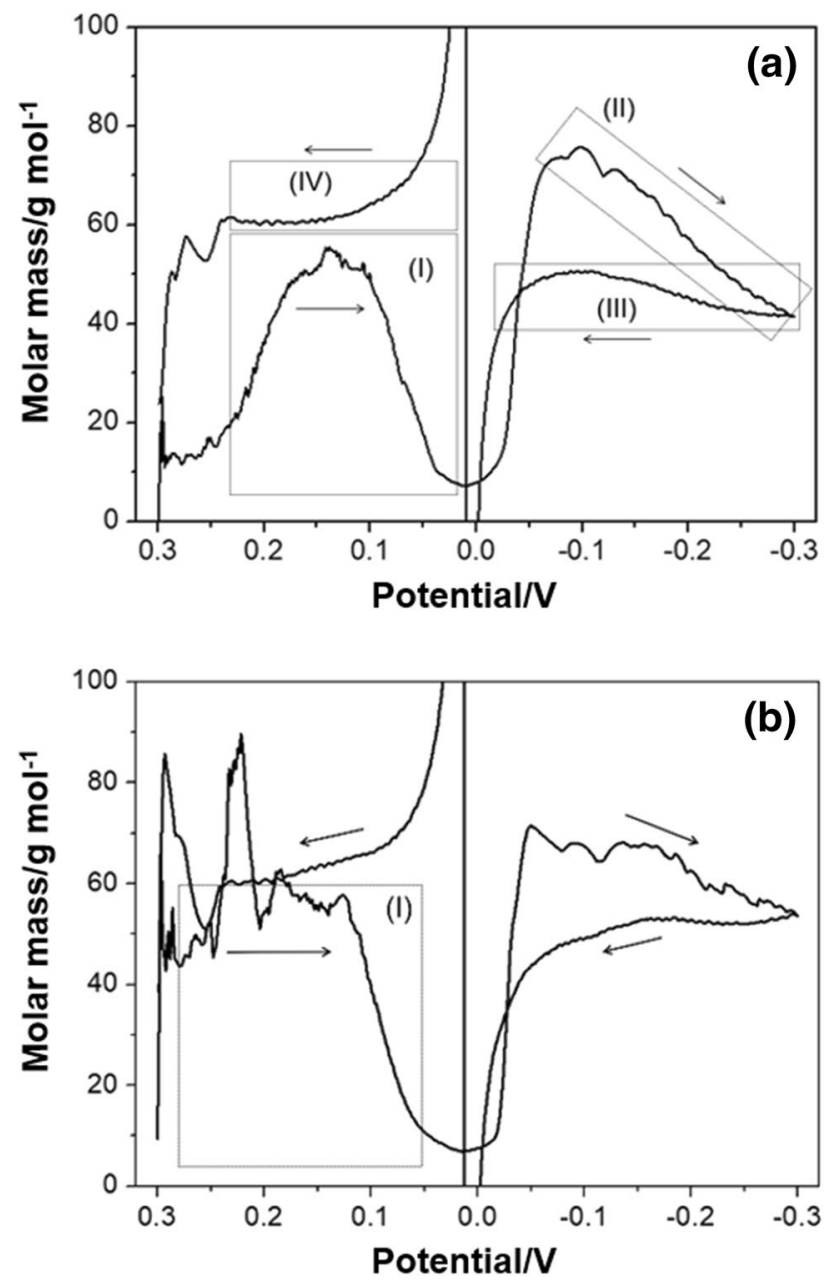

Fig. 3 Change of molar mass of deposited species during the first voltammetric cycle of copper deposition/dissolution a with no CNTs in solution, and $\mathbf{b}$ in the presence of $\mathrm{HO}_{2} \mathrm{C}$-MWCNTs. For a, the values of molar mass were calculated from the first derivative of the masscharge curve of Fig. 2. Sections (I), (II), (III), and (IV) correspond to those reported in Fig. 2. For $\mathbf{b}$, the values of molar mass were calculated from Fig. S3c. Section (I) in $\mathbf{b}$ is highlighted for comparison with the same section in $\mathbf{a}$

each section, it is necessary to explain the presence of a spike line at the center of the plot of Fig. 3a. This spike line (evident in Figure S5) is due to the inversion of slope at the vertex point of the $m-q$ curve (tip point $P$ in Fig. 2). For this reason, valuable information can only be extrapolated from those parts of the curve away from the spike, namely, sections (I), (II), (III), and (IV). Section (I) shows a rapid increase of molar mass to reach about $55 \mathrm{~g} \mathrm{~mol}^{-1}$ (c.f., copper atomic mass, $M_{C u}=63.54 \mathrm{~g} / \mathrm{mol}$ ); this increase is related to the underpotential deposition (UPD) of a copper adlayer between 0.20 and $0.10 \mathrm{~V}$ [26-28]. The inset of Fig. 1a clearly shows the presence of a reduction peak in the same voltage range; both symmetric shape and full width at half maximum $(35 \mathrm{mV})$ would suggest the reduction of adsorbed copper ions [29]. Section (II) corresponds to the deposition of copper at the main reduction peak of Fig. 1a. Interestingly, the calculated molar mass goes from about 75 to about $40 \mathrm{~g} \mathrm{~mol}^{-1}$; this follows from the change of slope in section (II) of the $m-q$ curve (Fig. 2). The average molar mass value of this section is around $59 \mathrm{~g} \mathrm{~mol}^{-1}$, close to the atomic mass of copper. This wide range of molar mass values is likely related to changes in surface roughness of deposited copper. It is known that roughness can affect the EQCM response when copper is deposited at different current densities [30]. Copper deposits formed at lower current density are rougher and the measured mass is correspondingly larger [30-32]. A similar behavior is observed here: at the onset of the reduction peak (where the current density is lower) the measured molar mass is larger than the expected value for copper, while the molar mass drops rapidly as the current density increases. We believe that this drop is due to competitive hydrogen evolution from the reduction of protons (especially at $\mathrm{pH} 1$, as in the present case). Charge is consumed for proton reduction but no mass is deposited since hydrogen bubbles are formed at the electrode surface $[33,34]$, thus the molar mass drops well below that of copper. For the same reason, section (III) in Fig. 3a lies below $50 \mathrm{~g} \mathrm{~mol}^{-1}$ rising as the potential becomes less reductive as less hydrogen evolves from the electrode. Finally, section (IV) corresponds to the dissolution of copper with a plateau value of about $61 \mathrm{~g} \mathrm{~mol}^{-1}$, in this case during oxidation there is no influence from gas evolution and the value of molar mass is significantly closer to the atomic mass of copper.

\subsection{Electrodeposition of copper in the presence of $\mathrm{H}_{2} \mathrm{~N}$-MWNCTs}

Amine-functionalized MWCNTs were added to the copper solution $\left(10 \mathrm{mM} \mathrm{CuSO}_{4} / 0.05 \mathrm{M} \mathrm{H}_{2} \mathrm{SO}_{4}\right)$ and the dynamics of copper deposition/dissolution on EQCM gold electrodes was studied following the same procedure used in the absence of CNTs. Pristine (non-functionalized) MWCNTs were not tested since satisfactory dispersions (i.e., solutions with limited nanotube agglomeration) could only be prepared with functionalized CNTs. When $\mathrm{H}_{2} \mathrm{~N}-\mathrm{MWNCTs}$ are in solution, the cyclic voltammograms of copper deposition/ dissolution are like those recorded in the presence of copper ions only. From a comparison of Figs. S1a and S1b, the peaks of UPD of copper (enlarged in the insets) are of comparable heights and found in the same potential range. Interestingly, the shape of the main reduction peak at $-0.20 \mathrm{~V}$ is better resolved in the presence of $\mathrm{H}_{2} \mathrm{~N}-\mathrm{MWNCTs}$, the current density is also higher 1.86 vs. $1.68 \mathrm{~mA} \mathrm{~cm}^{-2}$ with and without CNTs, respectively. On the other hand, the oxidation currents at $0.30 \mathrm{~V}$ are of the same value at around $-2.5 \mathrm{~mA} \mathrm{~cm}{ }^{-2}$. This difference is due to hydrogen evolution during the reduction sweep, hydrogen that cannot 
be oxidized back in the anodic sweep. It follows that the cathodic current is increased because of facilitated proton reduction in the presence of $\mathrm{H}_{2} \mathrm{~N}-\mathrm{MWNCTs}$. A case in support to this statement is presented hereinafter. In aqueous acidic solutions, the reduction of protons to hydrogen is a common competitive reaction during copper electrodeposition $[35,36]$. Thus, it is reasonable to assume that the total faradaic charge of electrochemical reduction $\left(q_{\mathrm{RED}}\right)$ consists of two contributions: (i) the cathodic charge of copper deposition $\left(q_{\mathrm{Cu}}\right)$, and (ii) the cathodic charge of hydrogen evolution $\left(\mathrm{q}_{\mathrm{H} 2}\right)$, where $q_{\mathrm{RED}}=q_{\mathrm{Cu}}+q_{\mathrm{H} 2}$. If all deposited copper is then dissolved during the anodic sweep, it follows that the total faradaic charge of oxidation $q_{\mathrm{OX}}=q_{\mathrm{Cu}}$ (note that water oxidation does not occur at $0.3 \mathrm{~V}$ ); hence the charge of hydrogen evolution can be estimated from $q_{\mathrm{H} 2}=q_{\mathrm{RED}}-q_{\mathrm{OX}}$ (in this analysis, the capacitive charge is considered negligible given the large amount of copper deposited/dissolved at the gold electrodes). To quantify the amount of hydrogen generated during copper electrodeposition, one needs to find the values of $q_{\mathrm{RED}}$ and $q_{\mathrm{OX}}$ from the experimental data, Fig. 4 shows how Mass $(m)$ and current $(j)$ are plotted against the charge $(q)$ passed through the cell during the deposition/dissolution of copper with and without CNTs in solution (the data used to construct these plots are taken from the fourth and fifth cycles of the $m-q$ and $j-q$ curves shown in Figs. S3 and S4). Figure 4a shows a full cycle of deposition and dissolution of copper without nanotubes in solution. The mass of copper deposited at the electrode (blue curve) increases when the current (red curve) is cathodic (positive values); instead when the current switches to anodic (negative values), copper is dissolved and the mass goes back to zero. The total faradaic charge of reduction is $q_{\mathrm{RED}}=106.6 \mathrm{~mA} \mathrm{~cm}{ }^{-2}$ where the maximum amount of copper has been deposited. The total faradaic charge of oxidation is $q_{\mathrm{OX}}=106.6-10.8=95.8 \mathrm{~mA} \mathrm{~cm}{ }^{-2}$, assuming the anodic current is essentially due to copper dissolution. The charge of hydrogen evolution is then $q_{\mathrm{H} 2}=q_{\mathrm{RED}}$ $-q_{\mathrm{OX}}=10.8 \mathrm{~mA} \mathrm{~cm}^{-2}$, i.e., the difference between the end of the anodic trace and start of the cathodic trace. The same considerations apply to the copper dissolution/deposition
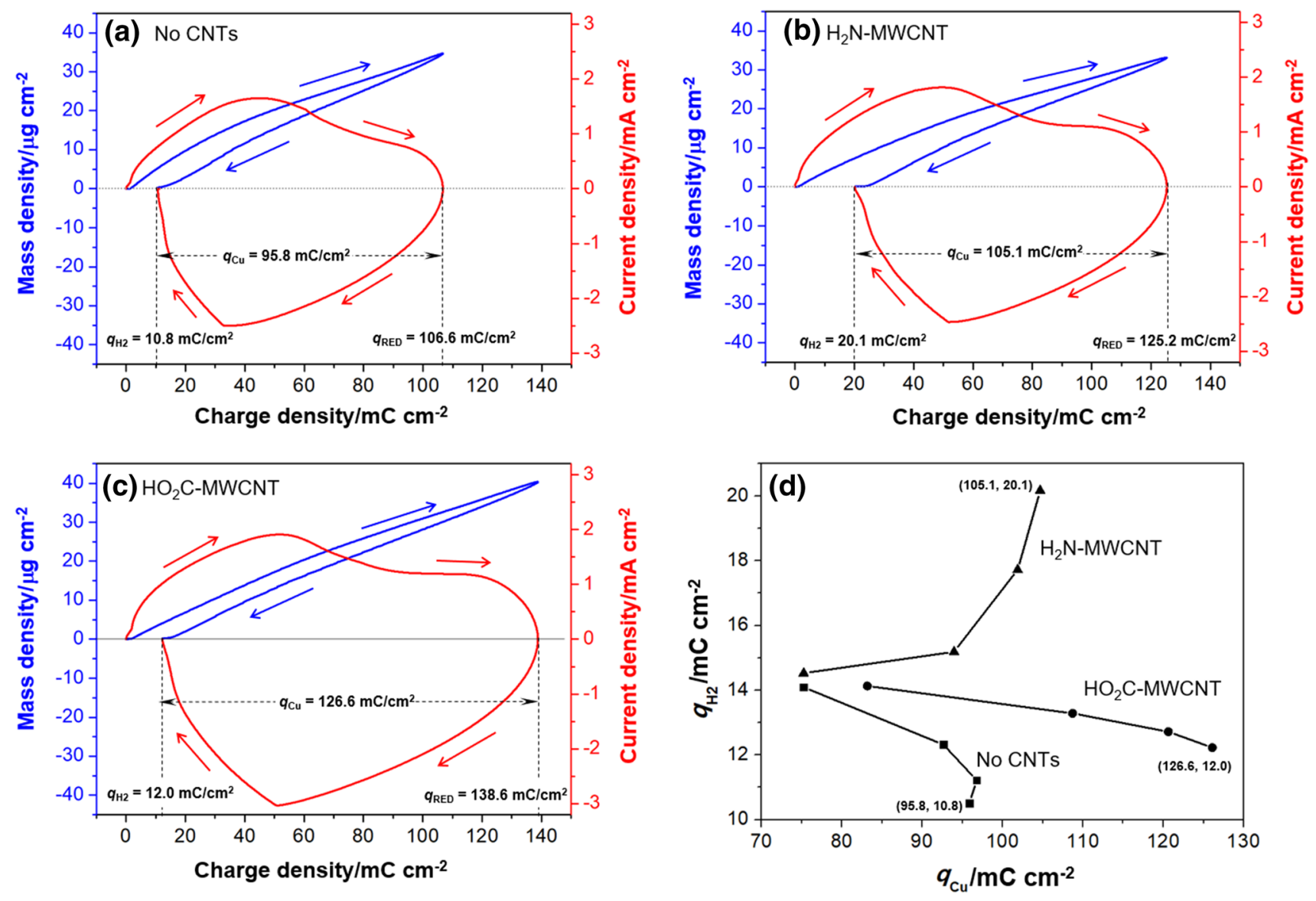

Fig. 4 Mass and current densities of a complete copper deposition/ dissolution cycle plotted against columbic charge recorded with a no CNTs, b $\mathrm{H}_{2} \mathrm{~N}$-MWNCTs, and $\mathbf{c} \mathrm{HO}_{2} \mathrm{C}-\mathrm{MWCNT}$ in solution. d Correlation between charge of hydrogen evolution, $q_{\mathrm{H} 2}$, a competitive

process to copper reduction, and charge of copper deposition, $q_{\mathrm{Cu}}$. The four points of each curve refer to four full copper deposition/dissolution cycles extrapolated from data presented in Figs. S3 and S4 
cycles in the presence of CNTs, as shown in Figs. 4b and $4 \mathrm{c}$. Furthermore, the same analysis can be applied to the first, second, and third cycles of copper deposition/dissolution using data from Figures S3 and S4, to give all $q_{\mathrm{H} 2}$ vs. $q_{\mathrm{Cu}}$ values reported in Fig. 4d. Figure $4 \mathrm{~d}$ shows the amount of charge consumed for hydrogen evolution, $q_{\mathrm{H} 2}$, against the charge used for copper deposition, $q_{\mathrm{Cu}}$, during electrochemical reduction. When no CNTs are present in solution, the amount of hydrogen produced at the electrode is lower when copper is deposited in large amounts. The opposite trend is observed when $\mathrm{H}_{2} \mathrm{~N}$-MWNCTs are present in solution, with more hydrogen evolution when the amount of deposited copper is larger. This finding supports the hydrogen evolution facilitating effect of $\mathrm{H}_{2} \mathrm{~N}-\mathrm{MWNCTs}$, with the amine functionalities being the likely cause of such a phenomenon. Comparing $\mathrm{H}_{2} \mathrm{~N}-\mathrm{MWNCT}$ s to $\mathrm{HO}_{2} \mathrm{C}-\mathrm{MWCNT}$ in Fig. $4 \mathrm{~d}$ strengthens this hypothesis: the carboxylic function does not increase hydrogen evolution, it does instead facilitate copper deposition. Amines are known for their hydrogen evolution enhancing effect on copper. Benzylamine in sulfuric acid aqueous solution decreases the activation energy of hydrogen evolution on copper from 94.6 to $33.0 \mathrm{~kJ} \mathrm{~mol}^{-1}$ [37], with aryl-ammonium ions adsorbed on copper inducing a highly effective surface concentration of protons [38]. We have observed comparable effects with polyallylamine adsorbed on copper foams enhancing hydrogen evolution at the expenses of $\mathrm{CO}_{2}$ reduction [39]. Similarly, polyethyleneimine adlayers improve hydrogen evolution on platinum due to protonation of the $-\mathrm{NH}_{2}$ groups in acidic media [40]. It follows that the main effect of $\mathrm{H}_{2} \mathrm{~N}-\mathrm{MWNCTs}$ is to enhance hydrogen evolution while the amount of deposited copper remains substantially unchanged. This is also evident from a comparison of Figures S3a and S3b; the maximum amount of copper deposited during the five voltammetric cycles is about $35 \mu \mathrm{g} \mathrm{cm}^{-2}$ with or without amine nanotubes in solution, while the total charge of reduction in the presence of $\mathrm{H}_{2} \mathrm{~N}-\mathrm{MWNCTs}$ is much higher, almost 200 $\mathrm{mC} \mathrm{cm}^{-2}$ versus $160 \mathrm{mC} \mathrm{cm}^{-2}$ when no nanotubes are used.

\subsection{Electrodeposition of copper in the presence of $\mathrm{HO}_{2} \mathrm{C}-\mathrm{MWCNTS}$}

The effect of carboxylic-functionalized MWCNTs on the electrodeposition of copper was examined following the same experimental procedure used without CNTs and in the presence of $\mathrm{H}_{2} \mathrm{~N}-\mathrm{MWNCTs}$. Cyclic voltammograms are given in Figure S1c; a UPD peak is again found at the start of the first cathodic sweep (c.f., insets of Fig. S1). More relevant, cathodic and anodic currents are enhanced in the presence of $\mathrm{HO}_{2} \mathrm{C}$-MWCNTs. Figure $3 \mathrm{~b}$ is a plot of the molar mass of species deposited during the first voltammetric cycle, this compares to that recorded in the absence of CNTs given in Fig. 3a. A major difference between the two plots was recorded in section (I), at the beginning of the cathodic sweep. A value of molar mass was immediately recorded in the presence of $\mathrm{HO}_{2} \mathrm{C}-\mathrm{MWCNTs}$, while it increased progressively to give a peak when no CNTs were present in solution. This change might be due to a surface interaction of $\mathrm{HO}_{2} \mathrm{C}-\mathrm{MWCNT}$ with the gold electrode, explaining the high variability of molar mass values recorded between 0.3 and $0.2 \mathrm{~V}$. Interestingly, the opposite change was observed when amine-functionalized MWCNTs were in solution, as shown in Fig. S5b. The interaction of $\mathrm{H}_{2} \mathrm{~N}-\mathrm{MWNCTs}$ with the electrode surface causes a drastic drop of molar mass falling below zero. Negative values of molar mass correspond to an increase in the oscillation frequency of the quartz crystal gold-coated electrode, which translates into a decrease of the mass of the electrode in terms of Sauerbrey equation [33]. Gold cannot be etched in the potential range used here; hence, the cause of this drop might rather be due to electrostatic interaction between protonated $\mathrm{H}_{3} \mathrm{~N}^{+}$-MWNCTs and the anodically polarized electrode. In the presence of $\mathrm{HO}_{2} \mathrm{C}-\mathrm{MWCNTs}$, the average values of molar mass recorded during copper deposition and dissolution are 63.1 and $63.2 \mathrm{~g} \mathrm{~mol}^{-1}$, respectively (Fig. S5c), in very good agreement with the molar mass of copper, $63.54 \mathrm{~g} \mathrm{~mol}^{-1}$. Also, these values are higher than those extrapolated with no CNTs in solution, 58.9 and $61.3 \mathrm{~g} \mathrm{~mol}^{-1}$, respectively (Fig. S5a), or in the presence of $\mathrm{H}_{2} \mathrm{~N}$-MWNCTs, 60.9 and $56.1 \mathrm{~g} \mathrm{~mol}^{-1}$ (Fig. $\mathrm{S} 5 \mathrm{~b})$. From this analysis, it appears that $\mathrm{HO}_{2} \mathrm{C}$-MWCNTs facilitate the formation of copper deposits in better agreement with the Sauerbrey equation, i.e., lower surface roughness as further discussed later in the paper. The amount of electrodeposited copper is strongly affected by the type of nanotubes present in solution. $\mathrm{HO}_{2} \mathrm{C}$-MWCNTs facilitate the deposition of $20 \mathrm{wt} \%$ more copper than $\mathrm{H}_{2} \mathrm{~N}-\mathrm{MWNCTs}$, 42.2 versus $34.4 \mu \mathrm{g} \mathrm{cm}^{-2}$, respectively, during the fifth cycle of deposition, as shown in Fig. 5a. The effect of the functional group is experimentally significant as shown in Fig. S6, where the differences between repeated copper depositions in the presence of the same type of nanotubes are significantly less than the difference between types of nanotubes. Data presented in Fig. S2 show that this is true for all cycles, the amount of copper deposited in the presence of $\mathrm{HO}_{2} \mathrm{C}-\mathrm{MWCNTs}$ is always greater compared to depositions from $\mathrm{CuSO}_{4} / \mathrm{H}_{2} \mathrm{SO}_{4}$ with no CNTs or with $\mathrm{H}_{2} \mathrm{~N}$-MWNCTs. This is also evident in Fig. 4d where the charge of copper deposition, $q_{\mathrm{Cu}}$, for $\mathrm{HO}_{2} \mathrm{C}-\mathrm{MWCNT}$ is larger reaching $126.6 \mathrm{mC} \mathrm{cm}^{-2}$ compared to 95.8 and $105.1 \mathrm{mC} \mathrm{cm}^{-2}$ for $\mathrm{CuSO}_{4}$ or with $\mathrm{H}_{2} \mathrm{~N}-\mathrm{MWNCTs}$, respectively. Furthermore, $\mathrm{HO}_{2} \mathrm{C}-\mathrm{MWCNTs}$ do not enhance proton reduction in contrast to $\mathrm{H}_{2} \mathrm{~N}-\mathrm{MWNCT}$, in fact the charge of hydrogen evolution, $q_{\mathrm{H} 2}$, progressively decreases as more copper is deposited on the gold electrodes. This highlights the fundamental role played by the type of functional groups during 

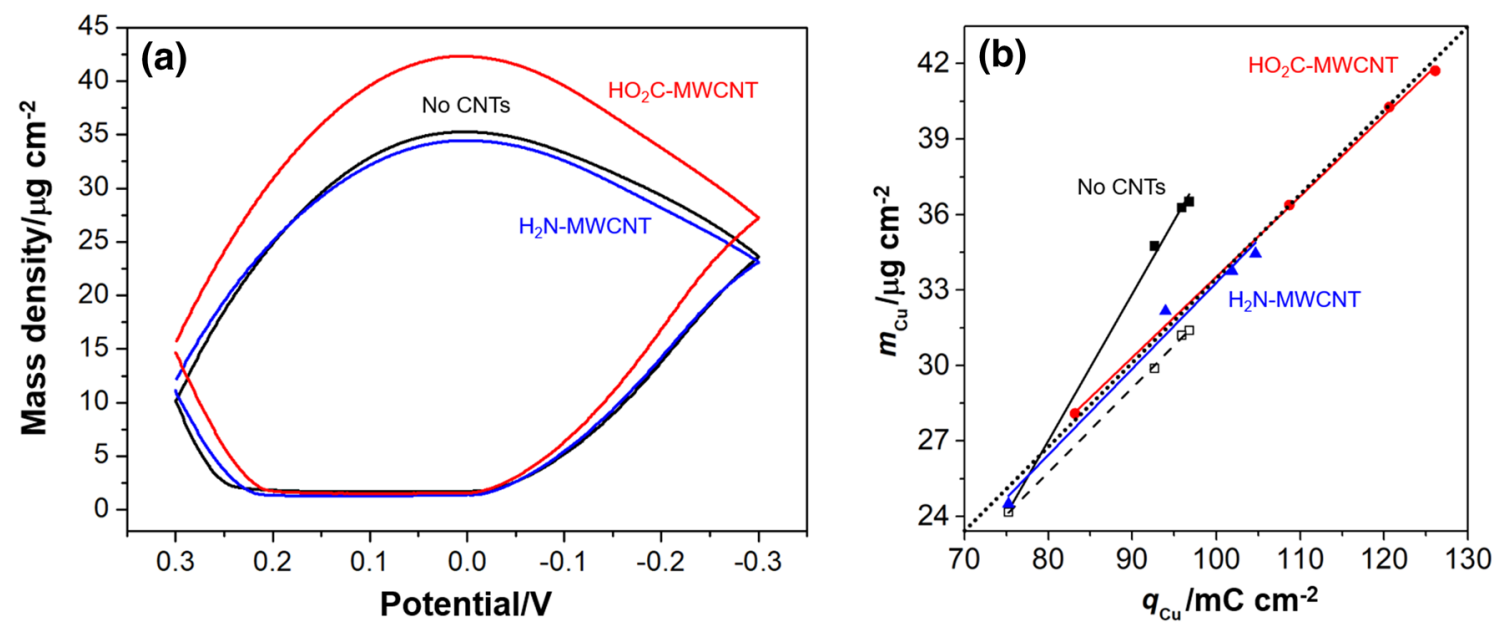

Fig. 5 Effect of carbon nanotube functionalization on the deposition of copper. a Comparison of deposited mass of copper, and $\mathbf{b}$ correlation between mass of copper $\left(m_{\mathrm{Cu}}\right)$ and charge of copper reduction $\left(q_{\mathrm{Cu}}\right)$ with no CNTs, or with $\mathrm{H}_{2} \mathrm{~N}-\mathrm{MWNCTs}$, or $\mathrm{HO}_{2} \mathrm{C}$-MWCNTs

the deposition of copper; carboxylic and amine groups have entirely different effects, which need to be considered in the design of copper-CNT electrochemical co-deposition processes.

$\mathrm{HO}_{2} \mathrm{C}-\mathrm{MWCNT}$ and $\mathrm{H}_{2} \mathrm{~N}-\mathrm{MWNCTs}$ appear to facilitate the formation of smoother copper deposits. Full sets of roughness data are provided in Tables S1, S2, and S3 of the ESM, and representative results are shown in Fig. 6 for convenience. In Fig. 6a1, b1, and c1, the SEM images show copper particles that are evenly distributed on the electrode surface with sparse distribution of larger particles when $\mathrm{HO}_{2} \mathrm{C}-\mathrm{MWCNTs}$ are used during deposition. In Fig. 6a2, $\mathrm{b} 2$, and $\mathrm{c} 2$, the roughness surfaces show flatter particles formed in the presence of $\mathrm{HO}_{2} \mathrm{C}-\mathrm{MWCNT}$ compared to $\mathrm{H}_{2} \mathrm{~N}$-MWNCTs or when CNTs are not used. To account for possible copper deposition inhomogeneity across the electrode surface area, eight different probing spots have been randomly selected and roughness parameters have been measured and averaged as shown in Tables S1, S2, and $\mathrm{S} 3$. Three key parameters $R_{a}$ (average roughness), $R_{p}$ (maximum profile peak height), and $R_{v}$ (maximum profile valley depth) have been calculated obtaining the following $\left(R_{a}, R_{p}, R_{v}\right)$ value sets: $(0.11,0.75,0.61)$ for copper deposits formed in the absence of CNTs, $(0.09,0.45,0.40)$ in the presence of $\mathrm{H}_{2} \mathrm{~N}-\mathrm{MWNCTs}$, and $(0.03,0.22,0.12)$ in the presence of MWCNT-COOH, all values in $\mu \mathrm{m}$. Clearly, $\mathrm{HO}_{2} \mathrm{C}-\mathrm{MWCNTs}$ forms smoother copper deposits.

Results in Fig. 5b confirm what is observed in the roughness measurements. Mass and charge of deposited copper were plotted to give three straight lines in the presence of CNTs and when $\mathrm{CuSO}_{4} / \mathrm{H}_{2} \mathrm{SO}_{4}$ was used without nanotubes in solution; all fitting data and results are provided in Table S4. The diagonal dotted line corresponds to the is solution. In $\mathbf{b}$, the diagonal dotted line corresponds to equation $m_{\mathrm{Cu}}=\left[M_{\mathrm{Cu}} /(2 F)\right] \times q_{\mathrm{Cu}}$, where $M_{\mathrm{Cu}}$ is the molar mass of copper and $F$ the Faraday constant. The dashed line is a correction of the experimental data for the deposition of copper with no CNTs in solution

theoretical mass of deposited copper at each charge value calculated from $m_{\mathrm{Cu}}=\left(M_{\mathrm{Cu}} \times q_{\mathrm{Cu}}\right) /(2 F)$. Clearly, the copper deposited in the presence of CNTs closely follows the theoretical values with both $\mathrm{H}_{2} \mathrm{~N}-\mathrm{MWNCTs}$ (blue line) and $\mathrm{HO}_{2} \mathrm{C}$-MWCNTs (red line) overlapping the diagonal line (results from linear fittings are presented in Table S4). Instead, the deposition from $\mathrm{CuSO}_{4} / \mathrm{H}_{2} \mathrm{SO}_{4}$ without nanotubes significantly deviates from the expected values. Larger masses are measured as $q_{\mathrm{Cu}}$ increases; this deviation is likely related to the roughness of the deposits formed in the absence of carbon nanotubes. As previously discussed, rougher copper deposits are affected by frequency and damping shifts with positive deviations from the Sauerbrey equation (i.e., larger measured masses) [30-32]. Correcting the experimental values with a multiplication factor of 0.86 brings the data parallel to the diagonal line (see open squares and dashed line); thus, roughness seems to cause an overestimate of mass of about $12 \%$. Instead, $\mathrm{HO}_{2} \mathrm{C}$-MWCNTs follow closely the theoretical response with larger amounts of smoother deposits. The facilitated deposition of copper on MWCNTs modified with oxygen-containing functional groups has been recently reported in literature [41]. Increased nucleation rate of copper and easy penetration of $\mathrm{Cu}$ ions between nanotubes were the main driving force for the formation of thicker copper deposits on oxidized MWCNTs. Our results appear to match this description where $\mathrm{HO}_{2} \mathrm{C}$-MWCNTs allow for a faster deposition (higher current densities) of more copper (larger deposited masses) compared to $\mathrm{H}_{2} \mathrm{~N}$-MWNCTs or without nanotubes in solution. Furthermore, our results appear to support the recently observed inclusion of oxidized MWCNTs in spherical $\mathrm{Cu}$ powders upon electrodeposition to form network architectures [22]. This is summarized in Reactions 2 and 3 where 
Fig. 6 Representative SEM images and roughness surfaces of copper deposited from $\mathbf{a 1}, \mathbf{a} 2$ $10 \mathrm{mM} \mathrm{CuSO}_{4} / 0.05 \mathrm{M} \mathrm{H}_{2} \mathrm{SO}_{4}$, b1, b2 $10 \mathrm{mM} \mathrm{CuSO}_{4} / 0.05 \mathrm{M}$ $\mathrm{H}_{2} \mathrm{SO}_{4}$ in $\mathrm{H}_{2} \mathrm{~N}-\mathrm{MWNCTs}$ supernatant, and c1, c2 $10 \mathrm{mM}$ $\mathrm{CuSO}_{4} / 0.05 \mathrm{M} \mathrm{H}_{2} \mathrm{SO}_{4}$ in $\mathrm{HO}_{2} \mathrm{C}$-MWCNTs supernatant. Data are taken from Table $\mathrm{S} 1-$ Spot 4, Table S2-Spot 4, and Table S3-Spot 8, respectively
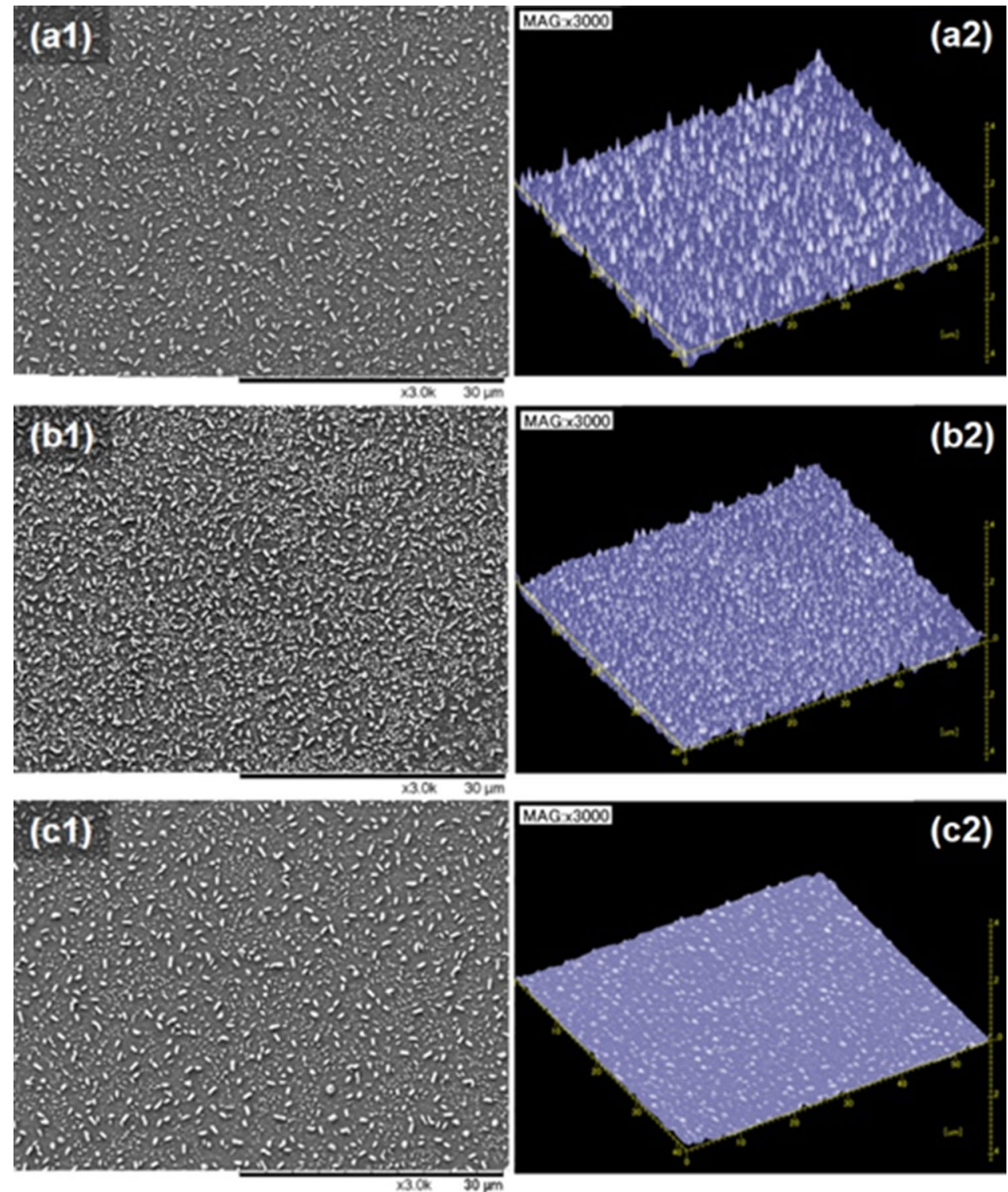

the functional groups present on the carbon nanotubes act as vectors of protons, in the case of amine, and of copper ions, in the case of carboxylate. At $\mathrm{pH} 1\left(0.05 \mathrm{M} \mathrm{H}_{2} \mathrm{SO}_{4}\right)$ aliphatic amine groups are fully protonated $\left(\mathrm{pK}_{\mathrm{a}} 9-11\right)$, whereas aliphatic carboxylic groups are partially deprotonated $\left(\mathrm{pK}_{\mathrm{a}} 4-6\right)$ and their negative charge is counterbalanced by copper ions.

Amine-facilitated hydrogen evolution:

$$
\begin{aligned}
& \text { Cathode }\left(\mathrm{e}^{-}\right)+{ }^{+} \mathrm{H}_{3} \mathrm{~N}-\text { MWCNT } \\
& \quad \rightarrow \text { Cathode }+{ }^{1} / 2 \mathrm{H}_{2}+\mathrm{H}_{2} \mathrm{~N}-\text { MWCNT. }
\end{aligned}
$$

Carboxylate-facilitated copper deposition:

$$
\begin{aligned}
& \text { Cathode }\left(\mathrm{e}^{-}\right)+{ }^{1 / 2} \mathrm{Cu}^{2+-} \mathrm{O}_{2} \mathrm{C}-\mathrm{MWCNT} \\
& \rightarrow \text { Cathode }+{ }^{1 / 2} \mathrm{Cu}^{0}+{ }^{-} \mathrm{O}_{2} \mathrm{C}-\text { MWCNT }
\end{aligned}
$$

\section{Conclusions}

Slow scan-rate cyclic voltammetry of gold EQCM electrodes in acidic solutions of diluted $\mathrm{CuSO}_{4}$ highlights the effect of MWCNT functionalization on the dynamics of copper deposition and dissolution. Copper deposition was observed in the voltage range from 0 to $-0.3 \mathrm{~V}$ during both cathodic and anodic sweeps. Dissolution of deposited copper was observed in the range from 0 to $0.3 \mathrm{~V}$, again in both anodic and cathodic sweeps. Carbon nanotubes were not incorporated in copper during deposition. The amount (mass) of deposited $\mathrm{Cu}$ increased in the presence of $\mathrm{HO}_{2} \mathrm{C}-\mathrm{MWCNT}$ dispersions in solution, no significant changes were recorded when $\mathrm{H}_{2} \mathrm{~N}-\mathrm{MWNCT}$ s were used instead. The increase of deposited mass was related to the facilitating copper nucleation effect of carboxylic 
species in solution as previously reported in literature. $\mathrm{H}_{2} \mathrm{~N}-\mathrm{MWNCTs}$ appeared to have an enhancing hydrogen evolution effect at cathodic potentials. Clearly, carbon nanotube functionalization should be closely considered in the design of electrochemical approaches for copper-carbon nanotube integration. This is particularly important in the engineering of $\mathrm{Cu}-\mathrm{CNT}$ composites with improved electrical transport performance where the incorporation of CNTs in copper can be affected by the type of functionalization or defects (i.e., integrity and purity) of the nanotubes.

Acknowledgements Financial support was provided by the Welsh Government through the Sêr Cymru II Recapturing Talent Fellowship Programme project number 80761-SU-029, the Sêr Cymru Chair Programme, the Office of Naval Research (N00014-15-2717), and the Robert A. Welch Foundation (C-0002).

\section{Compliance with ethical standards}

Conflict of interest The authors declare no competing financial interest.

Open Access This article is distributed under the terms of the Creative Commons Attribution 4.0 International License (http://creativeco mmons.org/licenses/by/4.0/), which permits unrestricted use, distribution, and reproduction in any medium, provided you give appropriate credit to the original author(s) and the source, provide a link to the Creative Commons license, and indicate if changes were made.

\section{References}

1. Subramaniam C, Yamada T, Kobashi K, Sekiguchi A, Futaba DN, Yumura M, Hata K (2013) One hundred fold increase in current carrying capacity in a carbon nanotube-copper composite. Nat Commun 4:2202

2. Janas D, Liszka B (2018) Copper matrix nanocomposites based on carbon nanotubes or graphene. Mater Chem Front 2:22-35

3. Feng Y, Burkett L (2015) Fabrication and electrical performance of through silicon via interconnects filled with a copper/carbon nanotube composite. J Vac Sci Technol B 33:022004

4. Todri-Sanial A, Ramos R, Okuno H, Dijon J, Dhavamani A, Wislicenus M, Lilienthal K, Uhlig B, Sadi T, Georigev VP, Asenov A, Amoroso SM, Brown AR, Pender A, Millar C, Motzfeld F, Gotsmann B, Liang J, Gonçalves G, Rupesinghe N, Teo K (2017) A survey of carbon nanotube interconnects for energy efficient integrated circuits. IEEE Circuits Syst Mag 17:47-62

5. Sundaram R, Yamada T, Hata K, Sekiguchi A (2017) Electrical performance of lightweight CNT-Cu composite wires impacted by surface and internal $\mathrm{Cu}$ spatial distribution. Sci Rep 7:9267

6. Wilhite P, Vyas AA, Tan J, Tan J, Yamada T, Wang P, Park J, Yang CY (2014) Metal-nanocarbon contacts. Semicond Sci Technol 29:054006

7. Milowska KZ, Ghorbani-Asl M, Burda M, Wolanicka L, Ćatić N, Bristowea PD, Koziol KKK (2017) Breaking the electrical barrier between copper and carbon nanotubes. Nanoscale 9:8458-8469
8. Wright KD, Barron AR (2017) Catalyst residue and oxygen species inhibition of the formation of hexahapto-metal complexes of group 6 metals on single-walled carbon nanotubes. C 3:17

9. Cho S, Kikuchi K, Lee E, Choi M, Jo I, Lee S-B, Lee S-K, Kawasaki A (2017) Chromium carbide/carbon nanotube hybrid structure assisted copper composites with low temperature coefficient of resistance. Sci Rep 7:14943

10. Dellinger JH (1911) The temperature coefficient of resistance of copper. Bull Bur Stand 7:71-101

11. Jayathilaka WADM, Chinnappana A, Ramakrishna S (2017) A review of properties influencing the conductivity of $\mathrm{CNT} / \mathrm{Cu}$ composites and their applications in wearable/flexible electronics. J Mater Chem C 5:9209-9237

12. Arai S, Osaki T (2015) Fabrication of copper/multiwalled carbon nanotube composites containing different sized nanotubes by electroless deposition. J Electrochem Soc 162:D68-D73

13. Arai S, Kanazawa T (2014) Electroless deposition of cu/multiwalled carbon nanotube composite films with improved frictional properties. ECS J Solid State Sci Technol 3:P201-P206

14. Arai S, Osaki T, Hirota M, Uejima M (2016) Fabrication of copper/single-walled carbon nanotube composite film with homogeneously dispersed nanotubes by electroless deposition. Mater Today Commun 7:101-107

15. Wright KD, Gowenlock CE, Bear JC, Barron AR (2017) Understanding the effect of functional groups on the seeded growth of copper on carbon nanotubes for optimizing electrical transmission. ACS Appl Mater Interfaces 9:27202-27212

16. Gowenlock CE, Gomez V, McGettrick JD, Andreoli E, Barron AR (2017) Surface-initiated growth of copper using isonicotinic acid-functionalized aluminum oxide surfaces. J Coat Technol Res 14:195-205

17. Arai S, Saito T, Endo M (2010) Cu-MWCNT composite films fabricated by electrodeposition. J Electrochem Soc 157:D147-D153

18. Arai S, Suwa Y, Endo M (2011) Cu/multiwalled carbon nanotube composite films fabricated by pulse-reverse electrodeposition. J Electrochem Soc 158:D49-D53

19. An Z, Toda M, Ono T (2016) Comparative investigation into surface charged multi-walled carbon nanotubes reinforced $\mathrm{Cu}$ nanocomposites for interconnect applications. Compos B 95:137-143

20. Arai S, Kato A (2013) Mechanism for codeposition of multiwalled carbon nanotubes with copper from acid copper sulfate bath. J Electrochem Soc 160:D380-D385

21. Arai S, Ozawa M, Shimizu M (2016) Fabrication of three-dimensional (3D) copper/carbon nanotube composite film by one-step electrodeposition. J Electrochem Soc 163:D774-D779

22. Wang Z, Cai X, Yang C, Zhou L, Hu C (2018) An electrodeposition approach to obtaining carbon nanotubes embedded copper powders for the synthesis of copper matrix composites. J Alloys Compd 735:1357-1362

23. Bard AJ, Faulkner LR (2001) Electrochemical methods: fundamentals and applications, 2nd edn. Wiley, New York

24. Elgrishi N, Rountree KJ, McCarthy BD, Rountree ES, Eisenhart TT, Dempsey JL (2018) A practical beginner's guide to cyclic voltammetry. J Chem Educ 95:197-206

25. Grujicic D, Pesic B (2002) Electrodeposition of copper: the nucleation mechanisms. Electrochim Acta 47:2901-2912

26. Hachiya T, Honbo H, Itaya K (1991) Detailed underpotential deposition of copper on gold(III) in aqueous solutions. J Electroanal Chem Interfacial Electrochem 315:275-291

27. Hölzle MH, Retter U, Kolb DM (1994) The kinetics of structural changes in $\mathrm{Cu}$ adlayers on $\mathrm{Au}(111)$. J Electroanal Chem 371:101-109

28. Deakin MR, Melroy O (1988) Underpotential metal deposition on gold, monitored in situ with a quartz microbalance. J Electroanal Chem Interfacial Electrochem 239:321-331 
29. Honeychurch MJ, Rechnitz GA (1998) Voltammetry of adsorbed molecules. Part 2: irreversible redox systems. Electroanalysis $10: 453-457$

30. Bund A, Schneider O, Dehnke V (2002) Combining AFM and EQCM for the in situ investigation of surface roughness effects during electrochemical metal depositions. Phys Chem Phys 4:3552-3554

31. Wehner S, Wondraczek K, Johannsmann D, Bund A (2004) Roughness-induced acoustic second-harmonic generation during electrochemical metal deposition on the quartz-crystal microbalance. Langmuir 20:2356-2360

32. Serizawa N, Kobayashi Y, MiyashiroH Katayama Y (2018) Deposition and dissolution of copper on a quartz crystal resonator in contact with a separator. Electrochemistry 86:250-253

33. Buttry DA, Ward MD (1992) Measurement of interfacial processes at electrode surfaces with the electrochemical quartz crystal microbalance. Chem Rev 92:1355-1379

34. Zhang XH (2008) Quartz crystal microbalance study of the interfacial nanobubbles. Phys Chem Chem Phys 10:6842-6848

35. Gabe DR (1997) The role of hydrogen in metal electrodeposition processes. J Appl Electrochem 27:908-915

36. Nikolić ND, Popov KI (2010) Hydrogen co-deposition effects on the structure of electrodeposited copper. Electrodeposition 48:1-70
37. Văduva CC, Vaszilcsin N, Kellenberger A, Medeleanu M (2011) Catalytic enhancement of hydrogen evolution reaction on copper in the presence of benzylamine. Int J Hydrog Energy 36:6994-7001

38. Văduva CC, Vaszilcsin N, Kellenberger A (2012) Aromatic amines as proton carriers for catalytic enhancement of hydrogen evolution reaction on copper in acid solutions. Int J Hydrog Energy 37:12089-12096

39. Ahn S, Klyukin K, Wakeham RJ, Rudd JA, Lewis AR, Alexander S, Carla F, Alexandrov V, Andreoli E (2018) Poly-amide modified copper foam electrodes for enhanced electrochemical reduction of carbon dioxide. ACS Catal 8:4132-4142

40. Xu GR, Bai J, Jiang JX, Lee JM, Chen Y (2017) Polyethyleneimine functionalized platinum superstructures: enhancing hydrogen evolution performance by morphological and interfacial control. Chem Sci 8:8411-8418

41. Chen X, Tao J, Yi J, Liu Y, Bao R, Li C (2018) Electrodeposited $\mathrm{Cu} /$ buckypaper composites with high electrical conductivity and ampacity. J Alloys Compd 735:163-171

Publisher's Note Springer Nature remains neutral with regard to jurisdictional claims in published maps and institutional affiliations.

\section{Affiliations}

\section{Ewa Kazimierska ${ }^{1}$ (D) Enrico Andreoli ${ }^{1} \cdot$ Andrew R. Barron ${ }^{1,2,3}$}

1 Energy Safety Research Institute, Swansea University, Bay Campus, Swansea SA1 8EN, UK

2 Department of Chemistry, Rice University, Houston, TX 77005, USA Department of Materials Science and Nanoengineering, Rice
University, Houston, TX 77005, USA 